\title{
Designing the Future Emergency Service Vehicle: Needs, Approach, Benefits and Competition
}

\author{
Jyri Rajamäki \\ Laurea SID Leppävaara, Laurea University of Applied Sciences Espoo, Finland \\ jyri.rajamaki@laurea.fi
}

Received: February 2013; Accepted: April 2013

\begin{abstract}
Public protection and disaster relief (PPDR) responders must manage on different emergency situations in land, water and air. Emergency response vehicles (ERVs) are specially equipped and on permanent standby for serious incident response. Modern ERVs are fully of electrical, electronic and ICT systems. However, there are possibilities of improvement in various aspects of ERVs. That will enhance performance, effectiveness and optimum usage of resources. The Finnish MOBI (Mobile Object Bus Interaction) research and development project aims to create a common international ICT infrastructure for all ERVs, based on better integration of ICT systems, applications and services. Another aim is to extend this project to other ERVs in European countries, permitting the standardisation of tools and technology in EU countries. One model that gives a practical and structured framework for innovation work is the NABC approach created by the Stanford Research Institute (SRI). NABC highlights the market needs, solution approach, solution benefits and competition dimensions of any solution being created. Our approach is to divide ERVs' ICT systems into four layers (a vehicle infrastructure and power management layer, a communications layer, a service platform and common services layer, and an actor-specific services layer) between which have standardised interfaces. The benefit is that open standards ease especially small and medium enterprises coming to the business, which improves on
\end{abstract}

Journal of NBICT, Vol. 1, 23-42.

doi: 10.13052/NBICT.2015.002

(C) 2015 River Publishers. All rights reserved. 
supply of new PPDR ICT products and degreases their prizes. In addition to cost savings, interoperability and availability of new PPDR ICT services improves. Traditionally good cooperation between different authorities in Finland enables development for the whole PPDR sector at the same time. This paper applies NABC framework for evaluating the on-going MOBI project and its results so far, and ensuring that the project continues as a right direction.

Keywords: disaster relief; emergency service vehicle; NABC analyse; PPDR; public protection; public safety; public safety communications.

\section{Introduction}

In emergency situations, citizens need to be able to get emergency services without any delay. In responding to civil emergencies and natural disasters, frontline public protection and disaster relief (PPDR) agencies, and voluntary organisations involved, need to have special emergency response vehicles (ERVs). The ERV is intended to transport personnel and equipment to the scene of an emergency for the purpose of patrolling, rescuing occupants and conducting rescue operations.

\section{A. Overview of PPDR in Finland}

In this article, PPDR functions are illustrated using the Finnish context. Finnish population of nearly 5.4 million is distributed unevenly; $60 \%$ is located in Southern Finland and particularly the capital region is heavily populated, whereas $40 \%$ is geographically unevenly distributed to Middle to Northern Finland. In addition, regional differences exist in Middle to Northern Finland. However, the scarce population in Northern Finland does not make it less prone to major incidents. Lapland is an internationally popular tourist location where potential for major emergencies exists, e.g. in case of a transnational traffic accident. Distances are long for getting special assistance; e.g. Ivalo is nearly $1000 \mathrm{~km}$ away from Helsinki. Therefore, Finland has exercised cooperation in emergency response with Barents region countries also in order to ensure preparedness and resourcing in major incidents. The distribution and number of PPDR organizations and personnel with different capabilities is uneven. This poses challenges in responding to the incidents with equal response time and resourcing. All these considerations have an influence on the properties of ERVs. 
As most European countries, Finland has an emergency telephone number 112 , which is used to summon the emergency services to any incident. A number of public, private, and voluntary emergency services are operating inemergency situations. These organizations provide emergency response centers (ERCs) with their response plans for different types of incidents and update the plans accordingly [1]. In an emergency situation, the agencies move to the response phase, where they execute their plans. Finland has 22 regional rescue departments, which are responsible for areal emergency and rescue services. Emergency medical services (EMS) have been outsourced for private companies in 200 municipalities, in 60 municipalities EMS are being carried out by regional rescue departments and in 40 municipalities the EMS is provided by the municipality itself [2]. Finland has 24 local police departments and 5 national units; Security Police, the National Bureau of Investigation, the National Traffic Police, Police Technical Centre and Police College of Finland [3].

Finnish TETRA-based PPDR network VIRVE is fully operative since 2002 with full domestic interoperability. It has 1350 sites which all are electromagnetic pulse (EMP) protected with back-up power supplies. The usage is composed of rescue services (33\%), police (21\%), border guards $(5 \%)$, customs $(2 \%)$, military (15\%), social and health services (13\%), air traffic-SAR (1\%), joint command and control (2\%), other authorities (3\%) and other than authorities (4\%). Every week, VIRVE transmits 800,000 group calls and 32 million short data service (SDS) messages. The Finnish experience shows that GSM networks were overloaded during emergency situations, such as high school massacres in 2007 and 2008 and summer storms in 2010, whereas the VIRVE network was operating normally. Mobile data is essential within PPDR field operations. In consequence of increasing cooperation between PPDR organisations, more data will be transmitted. In the near future, Finland is developing several new data systems for PPDR: 1) joint command and control system in 2013 - 2015,2) joint data system for investigating authorities in 2013 - 2015 and 3) joint field-command application in $2013-$ 2015. These systems will increase transmission of situational pictures, which means much more data transfer. The master plan in Finland is to close fixed police stations and create a mobile office concept for police, which also means more data transmissions. According to Finnish authorities, the past experience shows a clear need for a dedicated PPDR mobile data network which is not dependent on public mobile networksand which should have $100 \%$ state funding. PPDR and Citizens mobile broadband networks must be separate, or at least there should be secure priority functions [4]. 


\section{B. On-going Finnish ERV Development Projects}

The target of a Finnish national research, development and innovation programme 'Mobile Object Bus Interaction (MOBI)' is to create a common ICT hardware and software infrastructure for all emergency response vehicles. This infrastructure includes devices for voice and data communications, computers, screens, printers, antennas, cablings, and additionally, interlinking with factory-equipped vehicles' ICT systems is researched. [5]

The programme consists of two industrial projects, two governmental projects and a research project that generates research data for all other projects by researching and documenting the needs and requirements of the users, power generation and supply and specifying the existing solutions. One industrial project, led by Cassidian Finland Ltd., implements a vehicleinstalled professional mobile radio concept for law enforcement, fire and rescue operations[6]. Another industrial project, led by Insta DefSec Ltd., develops secured software services. The project utilizes the results of the related research project and aims to develop product concepts which have potentials in both domestic and export markets. Additionally, Insta DefSec Ltd. will further develop its business model in order to be able to utilize growth potential of the product concepts [6]. With regard to governmental projects, Police Technical Center heads a pre-commercial procurement project aiming to develop a new police car that is also a mobile office. HALTIK leads a project which goal is a common field command system for all Finnish PPDR actors.

The MOBI research project is a three year (9/1/2010-8/31/2013) project involving collaborative work between Laurea University of Applied Sciences, Police Technical Center (initiator of the project) and diverse industrial partners: Cassidian (secure communications; TETRA), Insta DefSec (IT service provider for public safety), Ajeco (secure communications; multichannel routers and their protocols) and Sunit (in-vehicle computers and displays). MOBI will address the above issues through a user-centred program of research that will culminate in new recommendations and designs for an integrated platform for use in ERVs. [5]

\section{Objectives and Form of the Paper}

The aim of this article is to provide an improved understanding of the structural characteristics and the dynamic evolution of the future ERV concept. The article is based on the results and lessons learned so far from the MOBI research and development project. The main sponsor of the project, the Finnish Funding 
Agency for Technology and Innovations - Tekes would like that the project and its results will be analysed according to the NABC (Need, Approach, Benefits and Competition) framework. The aim of this paper is to do this analysis. The author of the article acts as the scientific supervisor of MOBI.

The article has seven sections. After the introduction, the second section briefly introduces the NABC framework. The sections three to six evaluate the MOBI project and its results from the four viewpoints of the NABC framework. The last section concludes this paper summarizing the findings and looking future research needs.

\section{NABC Framework}

Multiple ways exist how innovations could be created and commercialized. One model that gives a practical and structured framework for innovation work is the NABC (need, approach, benefits and competition) framework created by the Stanford Research Institute (SRI) [7]. The NABC framework highlights the market needs, solution approach, solution benefits and competition dimensions of any solution being created. The goal of every innovation is to create and deliver customer value that is clearly greater than the competition's. During a research and development project whose goal is an innovation, the iterative use of the NABC framework ensures that the R\&D work concentrates on right issues. Iterative use of the NABC framework shown in Figure 1 is answering to the following questions.

What are the important customer and market needs? A need should relate to an important and specific user-client segment or a well identified market opportunity, with the market size and end customers clearly stated. [7].

What is the unique approach and compelling solution for addressing the specific client need? This should be drawn, simulated or made into a mockup to help convey the vision required. As the approach develops through iterations, it becomes a full proposal or business plan, which can include market positioning, cost, staffing, partnering, deliverables, a timetable and intellectual property (IP) protection. If a product is being developed, it must also include product specifications, manufacturing, distribution and sales. [7].

What are the client benefits of our approach? Each approach to a client's need results in unique client benefits, such as low cost, high performance or quick response. Success requires that the benefits be quantitative and substantially better - not just different. Why must we win? [7].

Why are our benefits significantly better than the competition? Everyone has alternatives. We must be able to tell our client or partner why our 

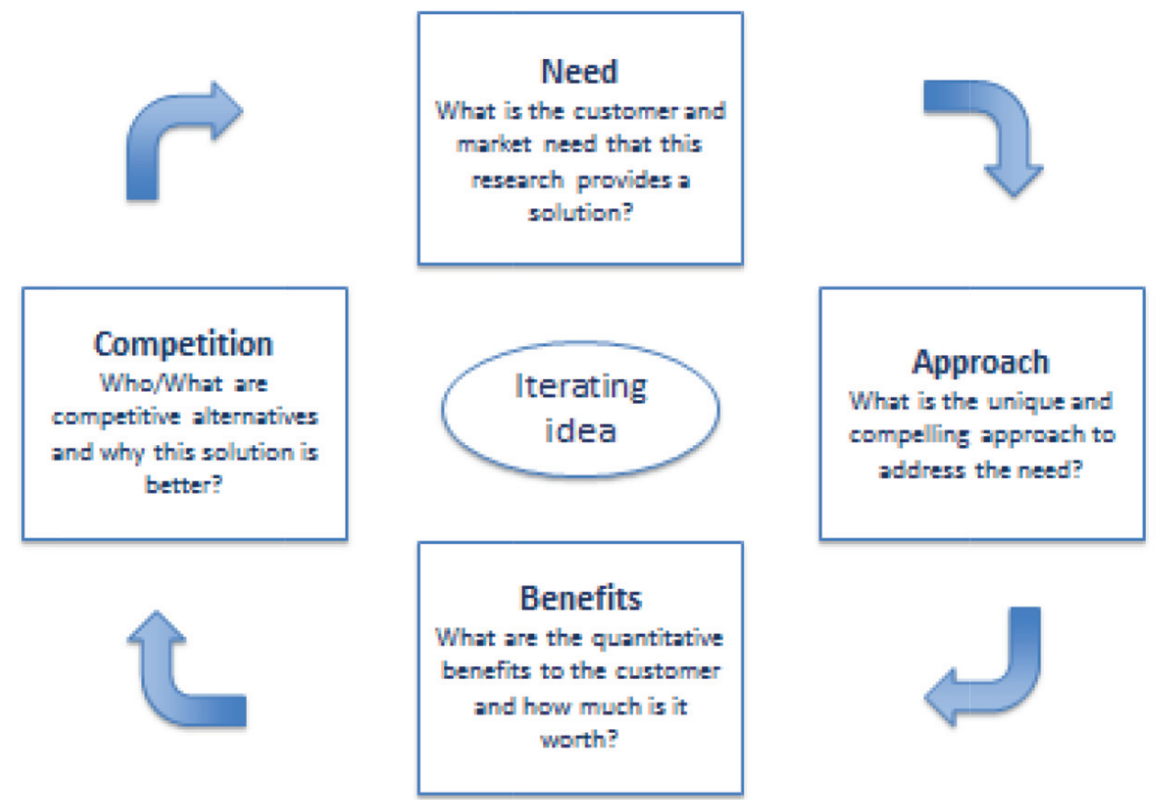

Figure 1 Iterative use of the NABC framework

solution represents the best value. To do this, we must clearly understand our competition and their value proposition and our client's alternatives. [7].

\section{Customer and Market Needs}

Within the MOBI project, we have surveyed the customer and market needs in which the research provides a solution. We have looked the needs from the point of view of 1) the citizens (end-users of the services provided via emergency response vehicles), 2) the PPDR organisations (procurers of ERVs), 3) the first responders (users of ERVs) and 4) industrial companies (providers of equipment, software and ICT services used in ERVs).

\section{A. Citizens' Needs}

The citizens need high quality PPDR services in ever changing environment. They want more value for their tax-paying money. In recent years, the productivity growth in the public sector has been much slower than in the private sector. In Finland, search and rescue (SAR) and emergency medical services (EMS) are carried out by municipal agencies or by private 
companies via public-private-partnership agreements. Today, municipals meet their increasingly aged population with rising health service costs. As all public services, there is a huge need for making EMS and SAR more effective.

LEAs (the Police, the Customs, the Border Guards) are state organisations. However, they have the same tax-payers than municipal actors and the same need to accelerate their processes of operate. Also, protection of citizens from more organised and internationalised crime requires new tools. Most of these new tools are used in the field, where ERVs are the hubs. Otherwise, citizens need services offered by police stations (license matters, reports of an offence, etc.). In the future, Finland will have less fixed police stations. This trend contributes towards a mobile office concept implemented via ERVs.

\section{B. PPDR Organisations' Needs}

Due to the economic situation in Europe, PPDR organisations' resources are meagre. For that reason, PPDR organisations' main need is to maintain their core services with significantly reduces budgets. The only realisable solution in view is better piggybacking of ICT. This means that also in field operations and thus in ERVs, ICT applications and services play more and more important role. In Finland, we have a trend that municipalities are united causing that also the number of municipal rescue departments is decreasing. This means that, with longer operational distances, first responders have less local expertise. For that reason, better technology assistance is needed. Also, modern ambulances are nearer mobile hospitals than just patient transferors. This induces more requirements for their ICT systems.

The European Commission, EUROPOL and FRONTEX have recognized that the two main challenges in European PPDR operations are the lack of interoperability and the lack of broadband connectivity. The lack of interoperability limits the effectiveness of PPDR responders in actual operations, and an evident lack of understanding as to whether these limitations arose from technology, operational procedures, and gaps in procurement or research. The capability of exchanging information (e.g. voice or data) is essential to improve the coordination of PPDR responders during their operations; especially, wireless communications are important in the response and mitigation of emergency crisis to support the mobility of first responders. [8].

Our research work has exploited former studies $[9,10]$ and development projects (such as TOTI, a multi-authority co-operation and information system, and KEJO, a command and control system of field units) and used them as one source of information. We have interview individual persons 
and groups from police, SAR, EMS and border guards, and identified the administrative and operative systems and defining the system priority and manageability requirements. In the event of a system or component failure, no effect on the performance or the safe operation of neither the vehicle nor its components must occur, especially with regard to brakes and steering. In addition, we have examined the required authority approvals for different invehicle systems; e.g. e-approval, RTTE- and EMC-directives. Our objective has been to produce an up-to-date description of the ICT-solutions used in Finnish ERVs.

Anyone who uses ERVs' ICT system has to be authenticated with his/her personal user ID or authenticated personal ID card. A suitable strong authentication method is needed. The ICT system should offer single signon authentication opportunities. The ICT system should support complex password configuration, or biometric authentication via e.g. fingerprints. The user disconnects the session by using the log out function. The user interface must be locked if the inactivity period is too long or the user is physically too far away from the system. Each user has access to the system depending the role what his/her duty or position required (e.g. end user, operational end user, technical support) [11]. The system must monitor every executed event according to the user role [12]. Successful and unsuccessful login event has to be logged in the system. The saved log data can be retrieved in a different format (MS-word, Excel, pdf) and can be used in problem solving situation. The log data has to save the user ID, timestamp and requested event, and exception events. The log data should be able to be saved in the system according to achieves act. The system must have the user interface to retrieve the $\log$ data report.

The communication system must have a secured protocol (such as https) and secured connections (such as secure sockets layer, SSL) within the local area, extranet and Internet as well as between each application. Virtual private network (VPN) connections should be available in the system. The system must have updated virus protection applications, and be protected from Internet hackers. All sensitive physical documents must be stored in the vehicles' locker locked. The ICT system's security components are not overlooked by anyone. The monitor needs to have privacy filters and screen protector to prevent spying eyes from reading information on the screen. All vehicles side windows have to be covered with interior window guards that are designed specifically to secure and fit to the interior window frame around the window. 
The policy of continuity and disaster recovery should exist. The policy defines the scope of continuity and disaster recovery strategy, defining boundaries by functional, operational and geographical alignment. All recognized risks that are likely to happen must be defined. The system must have adequate backups. The backup sequences can be configuring as needed. The system should have sustained operational test environment where the changes and their effects of the production system should be tested and approved beforehand. The continuity should be tested regularly.

\section{First Responders'Needs}

The main questions raised from the interviews of first responders were as following: Why ERVs' ICT applications cannot be simplified and rationalised to help PPDR responders' work more efficiently and effectively? Is it possible that two items of equipment be combined into one to make it easier to use and decrease power consumption?

When going to more detail requirements, ICT systems should be able to change a human machine interface (HMI) language (Finnish, Swedish and English in Finland). The systems should be able to generate any information, notice or warning in the same language as the HMI. The system navigation should be clear and easy to adopt. The user should be able to get 24/7 operational support related to the system. ERVs' hardware interfaces, such as a universal serial bus (USB), memory cards, printers and cameras, should support common standards. ERV's ICT system environment includes multiple software interfaces. Systems should be used simultaneously and systems should work seamlessly with all emergency relief systems and PPDR actors. Software interfaces should support internal information communication between PPDR vehicle systems and with other PPDR vehicles andactors. Software interface should support wireless usage and access from outside ofthe vehicle for authorized users. The field command system should be able to communicate with different secured mobile terminals and applications that have voice encryptions. Available applications must be seen clearly in the screen. The screen size and graphical resolution minimum requirement might be 1920x1080 / Full HD resolution in 15.5" and the NVIDIA GeForce GT 640M LE graphics card.

All ICT systems in ERVs should be reliable in all conditions. Natural conditions raise demands for ICT systems such as frost, heat, moisture, dust, shaking and vibration. ICT systems should be easy to use and properly located for operation usage. They should respond quickly to user integrationand user 
identification. Mission information queries and updates should be processed fast and reliable. Systems should not freeze during operation. System updates should be able to do wirelessly. Presented information should be verified and up-to-date. Information should be accessible fastand easy to transmit or broadcast to other units. All errors should logged and send to further analysing. Error handling should be automated and recover or reboot process should be fast. The ICT system should be compatible with major standards and / or "de facto systems". The system should be able to cope with a large variation of user volumes and be expanded as needed. Disturbances of other integrated applications should not disrupt the functionality of the system. All operations modules must be isolated from each other in such way that failure in a one subcomponent does not paralyze the whole system and the affected component can be restarted again.

ERVs rely strongly on mobile communication during operations. Communication solutions should fulfil several requirements that are somewhat contradictory thus somewhat challenging to develop in order to meet all the requirements stated. Communications must be robust in all situations. All features of the system must be error resistant so that a failure in one of the devices or networks does not paralyze the whole communications system. Most error situations should be resolved by the communications system itself not requiring any end-user input. The operational conditions and the location set requirements to mobile communication. Mobile communication equipment includes devices for both dedicate TETRA networks and public mobile operator networks. All dedicated and public technologies should be supported. ERVs' communication system should be able to select the suitable network based on availability, speed and the cost of a network (cost of data transfer per data unit) or utilize multiple networks parallel. New communications channels should be pluggable to the system as technology evolves. Connectivity to all ICT systems in the vehicle is required, including in-vehicle computers and video surveillance systems. Also, connectivity to external devices is needed, e.g. when the vehicle acts as a repeater (communications cell) for a portable device nearby. Communications channels and networks should be compatible with systems across borders. The software utilizing the communications connection must not be affected by a communications network vertical handover. Quality of service (QoS) for different kind of network services such as voice over IP (VoIP) or videostream is required. All communications must be secured with strong end-to-end encryption for preventing data capturing or inserting false data into the emergency system. The security module must beimplemented so that all systems can use it 
transparently. The module must be upgradeable, as a software or hardware component, if higher security is needed in the future.

Non-functional requirements, such as performance, reliability, availability, security, maintainability and portability, focus on how the system performs at the specific operation instead of what the system can do. However, in order to analyse, verify and to meet the needed non-functional requirements, measurements of the requirements should be declared. The rule of thumb could be that the network bandwidth should be a minimum of $100 \mathrm{MB}$ within the local area, extranet and the Internet. Mobility sets demands for power consumption of ICT systems. Vehicles' batteries should be able to produce sufficient power supply for all device's that needs electric power, a minimum of one hour without the engine running or external powersupply. All batteries should be able to be recharged in a short period of time.

\section{Private Companies' Needs}

From technology and service providers' point of view, the market of PPDR ICT products is too highly fragmented. LEA, SAR and EMS organisations have their own specifications that on top of everything else differ in every country. Development of a new ICT concept is significantly expensive, thus making the access to the international market is desirable. Standardisation is needed, because it eases especially small and medium enterprises (SME) coming to the business. That improves the supply of new PPDR ICT products and increases business opportunities.

\section{Solution Approach}

Our approach is to divide ERVs' ICT systems into four layers that have standardised interfaces shown in Figure 2. These layers are a vehicle infrastructure and power management layer, a communications layer, a service platform and common services layer, and an actor-specific services layer.

With regard to vehicle infrastructure and power management layer, two main areas to standardise are 1) services adopted from the standard vehicle systemand 2) special ERV installations. The services adopted from standard vehicle include for example power generation when the engine is on and information applied from the vehicle's CAN bus. The standardised ERV installations include vehicle body modifications, emergency lights and alarms, intelligent power management (power generation, storage and distribution systems) as well as cable and antenna installations (electromagnetic compatibility issues). 


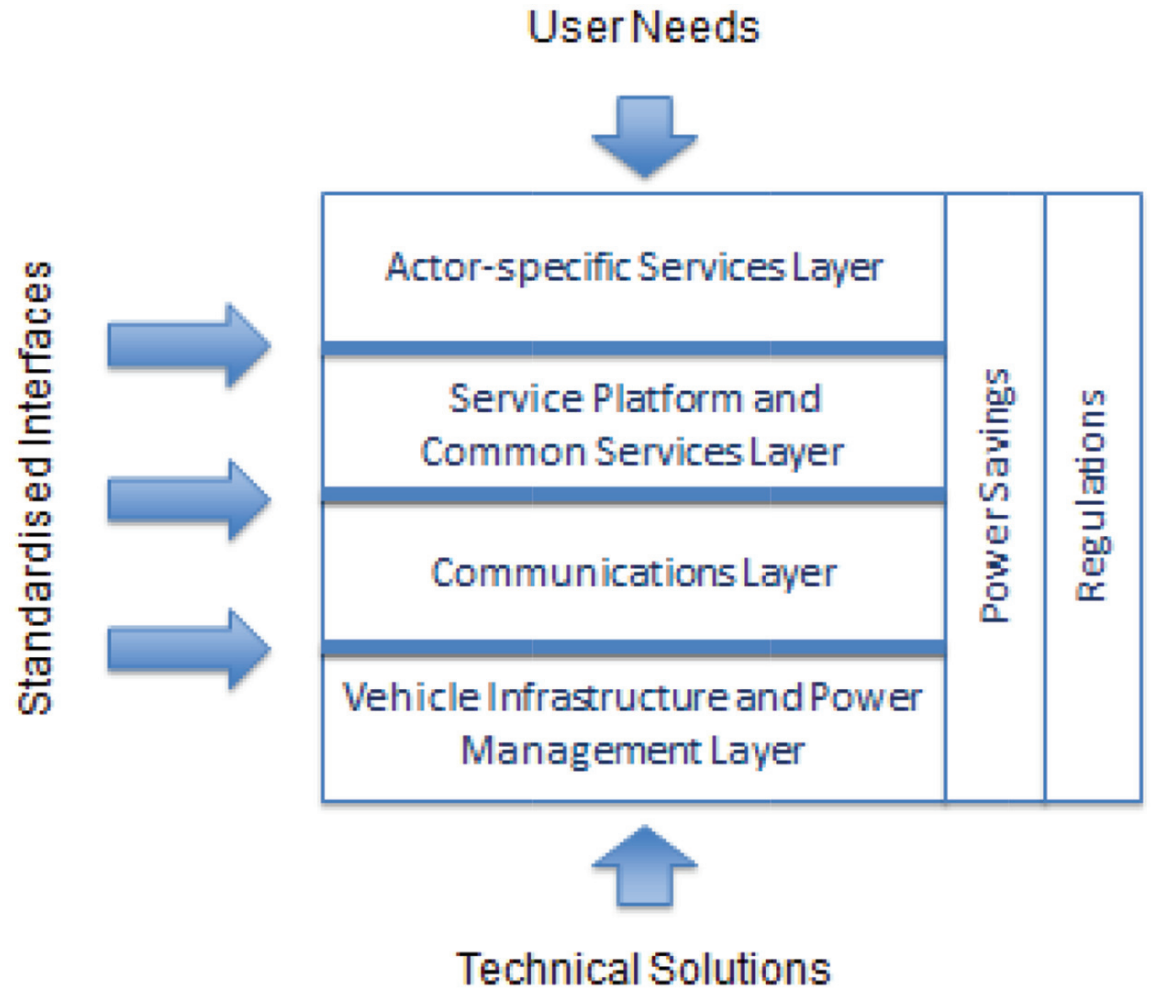

Figure 2 Layered approach to ERVs' ICT integration

ERVs' communications needs can be divided into long distance communications, local area networks and accessory communications. Furthermore, each category is scaled from light to heavy. ICT solutions have to be robust and easy to install. Special attention has to be paid to information security. Various encryption methods between different kinds of systems bring their own challenges to this project and its information security solutions. In addition, each PPDR actors have their own requirements regarding how to implement the information security into their ERVs' systems.

All ERVs have many similar applications such as a navigation system, patrol tracking, target maps, activity logs, alarms and remote access to central databases as well as controlling of blue lights and sirens, power supply systems, communications equipment. Roughly the common needs of the service platform and common services layer could be divided into two areas: decrease in the number of physical Human-Machine Interfaces (HMIs) and 
a common field command system for all PPDR actors. However, several physical HMIs are needed for different modes of operation. For example, the HMIs when driving at full speed should be totally different than those in mobile office mode where ergonomics act an important role.

With regard to actor-specific services, we have researched different PPDR actors' specific needs for services. For example, LEAs ought to have forensics technology for investigations and filed work. These kinds of technologies include advanced tracking systems that apply the Global Positioning System (GPS) to track criminals and their vehicles that have been tagged. This allows LEAs to keep track of suspicious activity that can help solving the case. We have widely studied these kinds of services in our SATERISK research project [13].

\section{Solution Benefits}

The benefits of our approach to the development of ERVs are similar than those that the OSI model brought to the field of data communications. The layered approach breaks ERVs' electrical, electronic, information and communication technologies into smaller and simpler part as well as smaller and simpler components, thus aiding component development, design and troubleshooting. The standardised interfaces allow modular engineering meaning that different types of hardware and software components communicate with each other. Interoperability between vendors allows multiple-vendor development through standardisation of ERV components. It defines the process for connecting two layers together, promoting interoperability between vendors. It allows vendors to compartmentalise their design efforts to fit a modular design that eases implementations and simplifies troubleshooting. The layered approach ensures the interoperability of technologies preventing the changes in one layer to affect to other layers, allowing quicker development and accelerating evolution. It provides effective updates and improvements to individual components without affecting other components.

\section{Competition}

The problems within the PPDR branch are similar in all the countries; for example the constant increments in ICT devices of ERVs. In this section, some of the most interesting ERVstandardisation and development projects are discussed. In the end of the section, these projects were compared with the MOBI project. 


\section{A. Overview of On-going ERVStandardisation and Development Projects}

The European Standard series EN 1846-x for "Firefighting and rescue service vehicles" has currently three parts that include Part 1: Nomenclature and designation, Part 2: Common requirements - Safety and performance, and Part 3: Permanently installed equipment - Safety and performance. The National Fire Protection Association (NFPA) is an international non-profit organisation that has a mission to reduce the worldwide burden of fire and other hazards on the quality of life by providing and advocating consensus codes and standards, research, training, and education. NFPA is responsible for 300 codes and standards that are designed to minimize the risk and effects of fire by establishing criteria for building, processing, design, service, and installation in the US and other countries. NFPA has twoERV-related standards: NFPA 414 "Standard for aircraft rescue and fire-fighting vehicles" and NFPA 1071-11 "Standard for emergency vehicle technician professional qualifications. The Ministry of Health and Long-Term Care of Ontario, Canada, has standardised the minimum acceptable requirements for land ambulances for use by an operator of a land ambulance service [14].

The Dutch Police's new surveillance car is the latest type of Volvo V70 specially equipped for highway patrol, having 330 horsepower with the top speed more than $250 \mathrm{~km} / \mathrm{h}$. It includes a number of new techniques and upgraded all the equipment. The software used by the police (current systems) is extended with pushed navigation software from "CityGis", an organization which develops special automatic vehicle location and navigation systems for emergency services. [15].

The National Safety Agency (NSA) of Australia has integrated technology into police patrol vehicles and command vehicles. Their police patrol vehicle concept provides significant benefits to jurisdictions seeking to use technology to improve their law enforcement capability. NSA's police patrol vehicle has been designed to allow greater functionality whilst reducing clutter inside the cabin. The technology integrated into the vehicle enables more work to be undertaken in the field. Overall the technology and purpose built interior increases officer safety as well as their operational effectiveness. A key feature is the NSA screen, a 12.1" purpose designed, sunlight readable LCD touch screen which is seamlessly embedded into the dash of the vehicle; all of the equipment included in the car is operated through this touch screen. The level of technology integration in the vehicle also provides superior surveillance capability. This includes automatic number plate recognition cameras, night 
vision cameras, speed detection equipment and biometric devices. A key risk of installing this technology would be vehicle battery drain. This has been overcome with the development of the power management system which enables a range of equipment to function without impacting the vehicle battery. All equipment is fitted to maintain resale value. NSA's command vehicle project will create a mobile command centre able to operate in remote locations for extended periods of time. The high level of connectivity in the vehicle enables communication with a central base and personnel in the field. Active repeaters fitted to the vehicle boost signal strength, supporting communications in the most remote areas. The vehicle is fitted with solar panels to ensure power is constantly generated so equipment will operate without being constrained by the vehicle's battery capacity. Power management systems also intelligently aid in extending the length of time the equipment is operational in the vehicle without impacting battery charge. The vehicle is fitted ready for deployment reducing response time when there is an incident. [16].

Association of Chief Police Officers (ACPO) Intelligent Transport Systems (ITS) Working Group identify and work towards emerging technologies to benefit the police services of England, Wales and Northern Ireland and have links with the ACPO Scotland. ACPO ITS lead a public-private partnership, to develop the One Box Single Vehicle Architecture [17] and Driver and Vehicle Data Management [18] concept and functional requirements for police, with on-going work to develop products showing how the data can be utilised to better manage the police vehicles and drivers proactively. This work is a part of police vehicle standardisation, increasing functionality and driving down cost to deliver a more cost effective approach to police transport fitment and procurement into the future. The concept ensures that equipment fitted adheres to the standard and is fit for purpose and functionality, creating a technology platform for the future.

\section{B. Comparision}

Different PPDR actors need different kind of ERVs; an ambulance differs from a police car. The current ERV-related standards specify the most of construction and design details including voice radio installation requirements. However, these standards entail no information about field command systems and interoperability requirements between different PPRD responders. According to our approach, although ERVs are different their communications layer as well as their service platform and common 
services layer could be identical. This enables interoperability between PPDR responders, at least at technical level.

The Dutch are aiming at the improvement the performance of the police patrol car when giving pursuit of criminals. Australians are developing different types of police vehicles for different tasks, one for patrol and another for command. In United Kingdom, ACPO ITS has quite similar approach than our MOBI project, but they also are focusing only on police vehicles.

The MOBI project advantages over other development projects are traditionally well operating and organized co-operations between Finnish authorities at different levels, e.g. national police - customs - border guard cooperation [19]. The project will enhance cooperation between the authorities through networking and the development of common processes. The project involves the authorities from the National Police Board, Police Technology Centre, Police College, Emergency Services College and the Border Guard. Also, individual experts from local police departments, regional rescue departments, customs, emergency response centers, emergency medical services and private security companies have taken part into MOBI development process.

Companies involved in the project have been working together with government as well as in the field of public administration with other actors. Finland has an atmosphere which supports successful innovation; e.g. Finnish companies are doing $R \& D$ with universities including their competitors, with the popular slogan: "Finland is a club, rather than a country" [20].

The harmonization of ICT services, cost and energy efficiency for the whole PPDR sector are the guiding factors for the project. Finland has evidences of success in developing wireless telecommunications, e.g. $1 \mathrm{G}$ - Nordic Mobile Telephone (NMM), 2G - Global System Mobile (GSM), 3G - Universal Mobile Telecommunications System (UMTS). Also, the world's first nationwide TETRA network, VIRVE is commonly used by Finnish authorities. Today, VIRVE enables the world's best interoperability between different PPDR services network-wise. Furthermore, Finnish authorities have extensive experiences in field command systems, e.g. the Police Field Command System POKE has been in operational use since 2006 [4]. From the base of the POKE system, a dedicated system 'PEKE' for fire and rescue work has been developed. 


\section{Conclusions}

\section{A. NABC Analysis}

A new PPDR vehicle concept could be seen as an innovation. When categorizing research findings by bringing the NABC logic and presentation of value creation in the context of PPDR vehicles, the following observations could be made.

Needs: PPDR along with other public sector organisations are facing significant pressures to maintain core services with significantly reduced budgets. Traditionally, PPDR has a large number and range of emergency response vehicles. These are mostly normal production vehicles that have been retrofitted with a wide array of aftermarket equipment, according to their role. Today, PPDR responders have more and more ICT facilities and applications in their vehicles. The traditional approach of individually wiring each stand-alone system resulted in expensive and cumbersome wiring looms and connectors. Why PPDR vehicles' ICT applications cannot be simplified and rationalized to help PPDR responders' work more efficiently and effectively? Can two items of equipment be combined into one to make it easier to use and decrease power consumption?

Approach: ERVs' ICT systems should be divided into four layers: the vehicle infrastructure and power management layer, the communications layer, the service platform and common services layer, and the actor-specific services layer. The interfaces between the layers should be standardised. The communications layer and the service platform and common services layer could be identical for all ERVs as against the vehicle infrastructure and power management layer is dependent on the vehicle type (e.g. saloon car or van) and the actor-specific services layer is dependent on PPDR actor (e.g. LEA or EMS).

Benefits: Open standards ease especially SMEs coming to the business, which improves on supply of new PPDR ICT products and degreases their prizes. In addition to cost savings, interoperability and availability of new PPDR ICT services improves.

Competition: Traditionally good cooperation between different authorities in Finland enables development for the whole PPDR sector. The supportive atmosphere enables productive co-operation between universities, authorities and companies. Finland has evidences of success in developing ICT systems; development of public mobile networks, the first nationwide TETRA network, POKE field command system. 


\section{B. Future Work}

The review of current ERVs emphasizes the design, services and solutions are working in normal conditions. There are effective implementation of services and solutions in existing ERVs across various spectrums. However, our research study shows shortcomings on various aspects, especially in challenging conditions. There are possibilities of improvement in various aspects of ERVs. That will enhance performance, effectiveness and optimum usage of resources. Research studies show that area of improvement including emergency response preparedness, critical communication and real time updates, optimization of power supply, availability of resources and equipment, safety and sustainability, ease of use and optimization of computer systems (hardware and software) are amongst those. The EVRs are used in different conditions and environments. Hence, considering end-users need is leading to better and sustainable services and solutions.

Next, the MOBI project will analyse a piece of equipment's user interface, taking into account such factors as its rights and needs and of the IT architecture design built into the vehicle, how it interacts with other necessary features and its security requirements. It will also take into account the user's skills and the services they use. The results will show what kind of features could be added to the PPDR, and what competencies are needed for use in different types of emergency situations. A demonstration vehicle will be fully equipped and used for tests and further research by the other business partners. Possible innovations could place more emphasis on the development of digital services rather than physical, the implementation of cable appliances, and increasing the versatility of equipment to make it suitable for different types of users.

\section{References}

[1] P. Linna, J. Leppäniemi, J. Soini and H. Jaakkola, "Harmonizing Emergency Management Knowledge Representation", Proceedings of PICMET'09, August 2-6, Oregon, USA, 2009.

[2] J-P. Honkanen, "Rajapinnasta keskipisteeksi", Suomen Lääkärilehti 11/2010 vsk 65, pp 84-86.

[3] S. Hätönen, "Police Field Commanding - The Role and Supportive ICT \& Communication System”, PSCE Conference, May 30-31, Espoo, Finland, 2012.

[4] H. Riippa, "The future of PPDR networks in Finland - Requirements and options", presentation in the EU workshop on The future of PPDR services in Europe, March 30, Brussels, Belgium, 2011. 
[5] MOBI - front page. Available at: http://mobi.laurea.fi/

[6] Tekes, Safety and Security Programme Projects http://www.tekes.fi/ programmes/Turvallisuus/Projects

[7] C. R. Carlson and W. W. Wilmot, Innovation: The Five Disciplines for Creating What Customers Want, 1st Ed., Crown Business, New York: Random House, 2006.

[8] G. Baldini, Report of the workshop on "Interoperable communications for Safety and Security”, Publications Office of the European Union, 2010.

[9] M. Rantama, "Pelastustoimenb langattoman tiedonsiirron tarpeet ja toteutusmahdollisuudet tulevaisuudessa”, Pelastusopiston julkaisu, B-sarja.Tutkimusraportit 2/2011.

[10] M. Rantama, "Mapping the future for Finland's rescue services", Tera Today, Issue 3, May 2011, pp 29-31.

[11] H-M. Sihvonen and T. Kurki, "Role Management Diversity in Emergency Situations", IEEE International Conference Technologies for Homeland Security, November 8-10, Boston, MA., 2010.

[12] T. Kurki and H-M. Sihvonen, "Role Management Approach for Emergency Organizations", The 45th Hawaii International Conference on System Sciences (HICSS-2012), January 4-7, 2012, Maui, Hawaii.

[13] J. Rajamäki, R. Pirinen and J. Knuuttila, Eds. SATERISK Risks of Satellite Based Tracking (Sample of Evidence Series, vol. 2). Helsinki: Edita Prima, 2012.

[14] Ontario Provincial Land Ambulance \& Emergency Response Vehicle Standard, Ministry of Health and Long-Term Care, Version 5.0, September 28, 2012. Available at: http://www.ambulance-transition. com/pdf_documents/standards_land_amb_emergency_response_vehicle standard.pdf

[15] "Politie koopt supersnelle auto's voor controle snelwegen," De Telegraaf, March 8, 2012.

[16] National Safety Agency - Home. Available at: http://www.nsaaust.com/

[17] One Box: Single Vehicle Architecture Criteria, Home Office Centre for Applied Science and Technology, Publication No. 39/11, St Albans, United Kingdom, 2011. Available at: http://www.homeoffice.gov.uk/ publications/science/cast/cast3911?view=Binary

[18] One Box: Driver and Vehicle Data Management System Criteria, Home Office Centre for Applied Science and Technology, Publication No. 28/12, St Albans, United Kingdom, 2012. Available at: http://www. 
homeoffice.gov.uk/publications/science/cast/crime-prev-communitysafety/cast2812?view=Binary

[19] A. Niemenkari, "Integrated border management - case Finland", Euromed migration II project, Februaryy23, Rome, Italy, 2010. Available at: http://www.euromed-migration.eu/e1152/e1483/e2556/e2585/ e2641/presen92NiemenkarM2s21feb2325rome2010.pdf

[20] V. Ilmavirta, "IPR management and industrial cooperation in the new Aalto University, the technology and innovation heart of the Otaniemi Science Park", Intelektinës Nuosavybës Valdymas Mokslo Ir Studijø Institucijose: Jo Vaidmuo Technologijø Perdavimo Procese, March 2, Vilna, Lithuania, 2010.

\section{Biography}

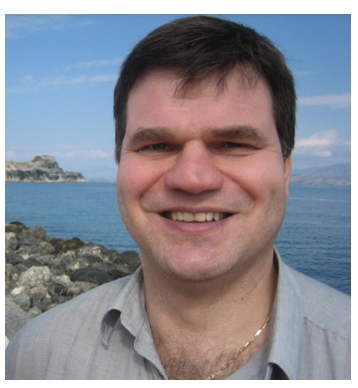

Jyri Rajamäki is a Principal Lecturer and the Head of Data Networks Lab at Laurea University of Applied Sciences. He has acted as the national coordinator and scientific supervisor of several public safety related research projects funded by EU, EURESCOM and Tekes - the Finnish Funding Agency for Technology and Innovation. He holds a PhD (Information Technology) from University of Jyväskylä and a D.Sc. (Electrical and Communications Engineering) from Helsinki University of Technology. 